\title{
A CONSTRUÇÃO DO DISCURSO AMBIENTAL NO CURTA-METRAGEM ILHA DAS FLORES
}

\author{
Rogerio do Amaral, Rosana Amaral Carrasco \\ Universidade do Oeste Paulista - UNOESTE, Mestrado em Meio ambiente e Desenvolvimento Regional (MMADRE), \\ Presidente Prudente, SP. . E-mail: professorrgamaral@gmail.com
}

\begin{abstract}
RESUMO
Este artigo tem o objetivo de analisar como o curta-metragem Ilha das Flores constrói o discurso sobre a exploração do meio ambiente. A metodologia empregada para atingir tal propósito consistiu na Análise do Discurso (AD). A AD partiu de uma pesquisa bibliográfica sobre questões ambientais e a observação do curta-metragem. Ao final da investigação depreendeu-se que Ilha das Flores monta o seu discurso de forma a evidenciar como no sistema capitalista, especialmente, o lucro sobre a produção de bens e serviços, altera a estrutura social, fato que coloca o ser humano desprovido de dinheiro abaixo dos porcos na lista de prioridade pela exploração do lixo, produzido pelo próprio ser humano.
\end{abstract}

Palavras-chave: lixo, porcos, seres humanos, capitalismo.

\section{THE CONSTRUCTION OF ENVIRONMENTAL DISCOURSE IN THE SHORT FILM ISLAND OF FLOWERS}

\begin{abstract}
This article have the objective to analyze how the short film Island of Flowers builds the discourse on the exploration of the environment. The methodology used to achieve this purpose consisted of Discourse Analysis (AD). The AD started with a bibliographical research on environmental issues and the observation of the short film. At the end of the investigation it was understood that Flores Island assembles his speech in order to show how in the capitalist system, especially, the profit on the production of goods and services, alters the social structure, a fact that puts the human being devoid of money Below the pigs in the priority list by the exploration of trash, produced by the human himself.
\end{abstract}

Keywords: Trash, pigs, humans, capitalism. 


\section{INTRODUÇÃO}

Este artigo pretende associar a teoria da análise do discurso à temática do meio ambiente com o propósito de levantar os mecanismos empregados na produção do discurso ambiental no documentário Ilha das Flores (1989). A preocupação com a degradação do meio ambiente é antiga, porém ainda nos deparamos com sucessivos crimes ambientais. Essa agressão ao meio ambiente coloca em evidência que os grandes grupos econômicos, em nome do lucro cada vez maior, produzem um discurso de que a exploração dos recursos naturais é primordial para nossa vida e, dessa forma, os resíduos depositados na natureza são consequências naturais do desenvolvimento. Diante desse quadro, pretende-se nesse artigo discutir como o contra discurso sobre as questões ambientais é produzido, elencando os elementos norteadores do cerne dessa discussão.

No que tange às discussões acerca do meio ambiente, Leff (2009) afirma que a complexidade ambiental, ou seja, a dificuldade de se discutir as questões sobre o meio ambiente, exige a criação de uma nova pedagogia, a qual implica uma reapropriação subjetiva do conhecimento. Portanto, na visão do autor não se pode analisar os problemas envolvendo o meio ambiente apenas da perspectiva científica, mas é necessário considerar também a realidade, o contexto, em que tais problemas se instalam, pois "O ambiente não é apenas o mundo de fora, o entorno do ser e do ente, ou o que permanece fora de um sistema. O ambiente é um saber sobre a natureza externalizada, sobre as identidades desterritorializadas, a respeito do real negado e dos saberes subjugados por uma razão totalitária [...]." (LEFF, 2009, p.21)

Para Ramalho (1996), os problemas ambientais estão relacionados com a deterioração das condições de vida da população. Dessa forma, na visão da autora, problemas com lixo, esgoto, ausência de saneamento básico ou poluição, são frutos de um ambiente social em desequilíbrio. Tal fato expõe grandes parcelas da população a um ambiente deteriorado, fazendo com que essas pessoas convivam com constantes riscos de desastres iminentes. Ilha das Flores não apresenta a ocorrência de desastres ambientais referentes ao descaso com o meio em que vivemos, mas evidencia a deterioração social, quando o ser humano é colocado abaixo dos animais.

Nesse sentido, o desequilíbrio socioambiental é fruto de um processo histórico que construiu diferenças e hierarquias, ou seja, resultado das relações desarmônicas entre os homens e a natureza e dos homens entre si. Dessa forma, o problema ambiental é "[...] de ordem política, já que se referem ao processo de organização social, de produção e consumo, da estruturação das instituições e dos espaços privados e públicos, das ações individuais e coletivas, bem como a das relações sociais em geral." (RAMOS; RAMALHO, 2016)

Já no que se refere à análise do discurso (AD), Fiorin (1995) afirma que cabe a ela explicar como um texto diz algo e também porque ele afirma tal fato. Portanto, o papel da análise do discurso é explicar quais as regras empregadas na constituição de sentido de um dado texto e o propósito de se apresentar tal sentido. Nessa pesquisa, tal conteúdo volta-se para a tentativa de compreender como se dá a produção do discurso na área do meio ambiente e de que maneira tal discurso impacta a exploração desse meio e consequentemente a sociedade.

Nesse sentido, pretende-se também verificar se a forma como o discurso é apresentado está adequado à maneira como o mesmo é construído, pois conforme afirma Gregolin (1995, p.17) "o discurso é um suporte abstrato que sustenta os vários textos (concretos) que circulam em uma sociedade." Ou seja, quando pensamos na forma como o discurso ambiental chega ao público, podemos afirmar que o texto retrata literalmente as ideias das personagens por trás de tal discurso ou vamos nos deparar com recursos linguísticos que mascaram o verdadeiro ideal de seus produtores, principalmente, quando pensamos nos discursos produzidos pelos autores que estão do lado dos exploradores do meio ambiente.

Na busca por esse esclarecimento, produz-se uma aproximação analítica entre o interno do texto, marcado pela forma de discurso, e o externo, centrado na relação entre o enunciado e a 
enunciação, pois de acordo com Gregolin (1995, p.18-19) "[...] podemos observar as projeções da enunciação no enunciado: os recursos de persuasão utilizados para criar a 'verdade' do texto [...]." Assim, pretende-se discutir como a questão da exploração ambiental, a produção cada vez maior de resíduos e a constante destruição da natureza aparece em textos da área ambiental, pois conforme afirma Gregolin (1995) produzir a análise do discurso é uma forma de explicar como o sentido de um texto é construído e a maneira como esse sentido se alinha com a história e a sociedade que o produz.

Segundo Orlandi (2005), a realização de uma análise do discurso permite ao leitor identificar como as relações de poder são significadas e simbolizadas no texto, o que nos abre a possibilidade de compreender de que forma determinados grupos sociais agem sobre os membros de sua comunidade na tentativa de impor seu modo de ver as coisas a todo um grupo social. Assim, por meio da AD torna-se possível verificar como a textualização do político se materializa no corpo do texto e quais os principais recursos discursivos que aparecem na construção do discurso ambiental.

Diante desse contexto, este artigo elege o curta-metragem Ilha das Flores, escrito e dirigido por Jorge Furtado, em 1989, como objeto de análise, com o objetivo geral de identificar como o discurso ambiental sobre a produção de resíduos é produzido pelo documentário, e os objetivos específicos de verificar as ferramentas predominantes desse discurso; analisar os elementos de resistência ao discurso do capital e debater a abrangência desse mecanismo na sociedade.

\section{METODOLOGIA}

Quanto à metodologia, esse artigo emprega a Análise do Discurso visando discutir como se dá a apropriação da linguagem pelo emissor e de que forma o mesmo constitui sua ação social em Ilha das Flores. Para tanto, parte-se de uma pesquisa bibliográfica buscando informações sobre questões ambientais, assim como sobre o conceito de AD e seus mecanismos de funcionamento em uma dada produção textual, apresentados na introdução desse artigo. A análise dos resultados se constitui por um cruzamento dos dados levantados a partir da revisão de literatura e as ferramentas discursivas encontradas na observação do curta-metragem analisado.

\section{RESULTADOS}

De forma geral, no curta-metragem Ilha das Flores nos deparamos com o relato de um tomate desde o momento em que ele foi plantado, colhido, transportado e vendido pelo produtor para um supermercado, local onde foi comprado por uma dona de casa que descobre que o mesmo está podre e acaba depositando-o no lixo. Essa saga do tomate se cruza com a história de porcos e seres humanos, com o objetivo final de estabelecer a diferença que existe entre tomates, porcos e seres humanos.

A Ilha das Flores, localizada à margem esquerda do Rio Guaíba, próxima a Porto Alegre, era o local onde se depositava grande parte do lixo produzido na capital gaúcha na década de 1980. Como relatado pelo curta-metragem, o lixo era depositado num terreno pertencente a criadores de porcos, cujos empregados separavam parte deste lixo para o consumo dos porcos. Enquanto esses empregados escolhiam entre o lixo aquilo que podia ser dado aos porcos, do lado de fora da propriedade crianças e mulheres formavam uma fila, esperando autorização para entrar na propriedade, onde tomavam entre a sobra do lixo, restos que utilizariam em sua alimentação.

O mais chocante dessa história consistia no fato de que essas filas eram enormes, o que levava os empregados a organizarem os catadores em grupos de dez pessoas que entravam na propriedade durante cinco minutos e pegavam o que conseguiam do lixo. Portanto, o curtametragem tem a intenção de denunciar como tal situação é absurda, isto porque, os seres humanos são colocados em posição inferior aos porcos no direito de se alimentar do lixo. Para isso, tem-se o relato sobre o processo de produção do tomate, a venda para o supermercado, a 
compra pelo consumidor, ser humano, que detecta que ele não tem condição para ser usado em uma refeição e o lança ao lixo, para que na Ilha das Flores, esse lixo volte a ser disputado pelos "seres humanos", porém, depois dos porcos.

Outra característica que se destaca no curta-metragem é a apresentação do conceito de todos os elementos apresentados, assim ao longo da história o telespectador se depara com o conceito de japonês, ser humano, tomate, dinheiro, Cristo, judeus, porco, dia, família, lixo, doença, ilha, água, flores. Todos esses conceitos reforçam a narrativa do tomate, desde sua origem na plantação do japonês, passando pelo descarte no lixo na casa da consumidora, até a "disputa" entre os porcos e os seres humanos na llha das Flores.

\section{DISCUSSÃO}

Apesar do curta-metragem Ilha das Flores não citar a palavra capitalismo em nenhum momento, seu enredo gira em torno desse modo de produção, pois a história parte da produção do tomate, vendido para o supermercado, lugar em que é adquirido por uma consumidora através do dinheiro que ela consegue vendendo perfumes, fato que remete à produção de flores, compradas pelas empresas de perfumaria para extrair a fragrância do perfume. Portanto, seguindo essa linha de raciocínio, o curta-metragem constrói o seu discurso quanto ao papel assumido pelo capitalismo no funcionamento da sociedade e consequentemente na produção de resíduos, cujo descarte por parte dos consumidores gera o problema ambiental e social tratado pelo documentário, o uso do lixo para tratar dos porcos e também dos seres humanos que lá formam filas para saciar uma condição de vida extremamente precária.

Além dessa estrutura, destaca-se também em Ilha das Flores a constante atribuição de conceito a todos os elementos ali apresentados, porém dentre essas definições é atribuída uma ênfase para o conceito de ser humano. O discurso nesse momento procura evidenciar a capacidade humana de pensar, faculdade distinta dos animais e que deveria colocar o ser humano acima dos demais seres que habitam nosso planeta. No entanto, com o desenvolvimento da história, percebe-se a intenção do roteiro em discutir se realmente pode-se considerar o ser humano como um ser acima dos demais, vide que apesar de sua racionalidade, o mesmo não é capaz de proporcionar condições de vida digna e igualitária para todas as pessoas.

A crítica à racionalidade humana também pode ser apreendida na ênfase que o roteiro do documentário dá ao ser humano enquanto gerador de lixo. Na história, observamos uma consumidora que comprou um tomate para preparar um molho que acompanharia uma carne de porco, porém essa mulher julgou que o tomate não era adequado para participar de sua refeição e este foi direcionado ao lixo, mas ao final nos deparamos com os porcos sendo alimentados por esse lixo, para onde o tomate tinha sido direcionado, ou seja, o discurso tem a intenção de determinar que no fim o tomate acabou sendo consumido pela mulher, cuja racionalidade não foi suficiente para evitar a geração de lixo, por meio do consumo da carne de porco que se alimenta dos restos do lixo.

Outra passagem relevante do curta-metragem e que retoma a discussão econômica-social em torno da produção de lixo encaminhado para a llha das Flores se refere à posição dos porcos em relação aos seres humanos que buscam ali um meio de sobreviver, pois os porcos hierarquicamente estão acima das mulheres e crianças, fato explicado novamente pela prática da atribuição de conceitos, pois ao conceituar dono, evidencia-se a posse de dinheiro e propriedade, enquanto as mulheres e crianças que buscam alimentos no lixo são caracterizadas como pessoas sem dinheiro e também sem dono, mas ao contrário do que se imagina não ter dono não atribui a essas pessoas liberdade e muito menos dignidade.

Em uma sociedade capitalista, o que determina a liberdade, compreendida aqui como a possibilidade de ser alguém na sociedade, é a quantidade de dinheiro ou de propriedades que a pessoa possui. Dessa forma, quem não tem bens acaba sendo classificada como inferior às posses 
dos donos, nesse caso, dos porcos que tinham o privilégio de comer antes e melhor do que os seres humanos. Por isso, o conceito da palavra livre "estado do quem tem liberdade" e ligado ao conceito de ser humano é discursivamente apresentado como uma ironia, pois no capitalismo só existe liberdade para aqueles que têm dinheiro e propriedade, caso contrário, até os porcos estarão a sua frente.

\section{CONSIDERAÇÕES FINAIS}

Conclui-se que o discurso ambiental produzido no curta-metragem Ilha das flores caracteriza-se como uma forma de crítica à maneira como o sistema capitalista de produção interfere no meio social, levando as pessoas a viverem em um ciclo contínuo de consumo e, consequentemente, de geração de resíduos. O documentário também evidencia nesse contexto capitalista, a desigualdade que o sistema promove entre as pessoas, cuja relevância passa a ser medida pela capacidade de consumir. Nesse sentido, percebe-se que o discurso em llha das Flores denuncia a deterioração social vivida por uma sociedade capitalista que não tem a capacidade de prover de forma igualitária todos os seus membros, o que torna parte dessa população depende do lixo produzido pelos abastados para manter sua sobrevivência.

Quanto ao impacto social provocado pelo discurso de Ilha das Flores, o mesmo toma duas direções. De um lado, como citado no parágrafo anterior, o filme enfatiza como o sistema capitalista de produção gera uma sociedade dividida em grupos econômicos, segundo a condição desses grupos em poder consumir e usufruir, dos produtos oferecidos pelo mercado. Por outro lado, há também no documentário uma crítica enfática para o fato de que os problemas ambientais se acentuam devido ao fato do ser humano, um ser considerado pensante, não ter a capacidade de analisar o quanto seu consumo excessivo pode agredir o meio ambiente com a geração excessiva de lixo. No mundo capitalista, um produto alimentício com característica inapropriada de uso em apenas uma de suas partes e descarto no todo, pois o mercado está ali do lado para que se consuma outro produto totalmente saudável.

Já no que se refere às relações de poder evidenciadas pelo discurso construído no curtametragem Ilha das Flores, em primeiro lugar, tem-se uma ênfase no fato de que o sistema capitalista gera a desigualdade entre os membros da sociedade, no entanto, no documentário explora-se de forma incisiva tal diferença, uma vez que aqueles que não possuem bens e propriedades não se tornam apenas inferiores aos sujeitos que possuem tais recursos, mas estão abaixo de qualquer elemento pertencente aos sujeitos abastados, como evidenciou o filme, no momento em que as mulheres e crianças foram colocadas abaixo dos porcos, que tinham donos, isto é, pertenciam a pessoas abastadas do sistema capitalista, no direito de explorar o lixo para se alimentar.

A segunda relação de poder evidenciada pelo documentário foi construída por meio da conceituação dos elementos discutidos pelo filme, mas principalmente, na ênfase dada ao conceito de ser humano e sua capacidade de raciocínio, pois tal habilidade deveria dar às pessoas condições de igualdade e de dignidade, no entanto, isso não ocorre. Na verdade, no sistema capitalista, além da desigualdade econômica, o ser humano ainda se encontra em uma condição indigna de vida, tornando-se necessário revirar o lixo, para ali encontrar resquícios de alimentos que permitam a sobrevivência de sua família. Portanto, de nada adianta possuir capacidade de reflexão e polegar opositor, se o mesmo não consegue elaborar uma vida digna para seus pares.

Por fim, relacionada a todos esses fatores discutidos nesse tópico, identifica-se também a presença de uma ironia no discurso do curta-metragem Ilha das Flores. Essa ironia reforça à crítica à capacidade de raciocínio humana, enfatizando que o ser humano é caracterizado como livre. Mas diante da situação narrada pelo documentário, que liberdade é essa, cujas pessoas na hierarquia do lixo, estão abaixo dos porcos, ou seja, reforça-se à ideia de crítica ao sistema capitalista de produção, cuja liberdade só existe para aqueles que conseguem alçar a ponta da 
pirâmide, tornando-se proprietários. Aos que não atingem esse patamar, o que resta é disputar as migalhas do lixo depois dos porcos.

\section{REFERÊNCIAS}

FIORIN, José Luiz. Tendências da análise do discurso. Cadernos de Estudos Linguísticos, Campinas, v.19, p.173-179, jul./dez., 1990.

ILHA DAS FLORES. Direção: Jorge Furtado. Produção: Monica Schmiedt e Nora Goulart. Intérpretes: Paulo José, Ciça Reckziegel, Júlia Barth e outros. Roteiro: Jorge Furtado. Música: extraída de O Guarani, de Carlos Gomes. Porto Alegre: Casa de Cinema de Porto Alegre, 1989. 13min07. Produzido por Casa de Cinema de Porto Alegre. Disponível em:

<https://www.youtube.com/watch?v=e7sD6mdXUyg>. Acesso em: 15 jul. 2017.

GREGOLIN, Maria do Rosário Valencise. A análise do discurso: conceitos e aplicações. Alfa, São Paulo, v.39, p.13-21, 1995.

LEFF, Enrique. Complexidade, racionalidade ambiental e diálogo de saberes. Educação e Realidade, v.34, n.3, p.17-24, set./dez, 2009.

ORLANDI, Eni P. Michel Pêcheux e a análise de discurso. Estudos da Língua(gem), Vitória da Conquista, n.1, p.9-13, jun. 2005.

RAMALHO, Deolinda de Souza. Vulnerabilidade e Riscos em Comunidades Urbano Marginais. Campina Grande: UFPB/UNCAL/IDRC, 1996.

RAMOS, Paulo Roberto; RAMALHO, D. A mídia do meio ambiente. 2016. Disponível em: <http://encipecom.metodista.br/mediawiki/images/7/7f/CTA2E_-_Texto_5__Paulo_Ramos_e_Deolinda_Ramalho.pdf>. Acesso em: 25 jul. 2017. 